\title{
Towards De-Colonial Agitations in University Classrooms: The Quest for Afrocentric Pedagogy
}

\author{
Bunmi Isaiah Omodan and Bekithemba Dube \\ University of the Free State \\ Republic of South Africa
}

\begin{abstract}
This study empirically conceptualised and rationalised decoloniality as a way to bridge the vacuumed of Americentric classroom hegemony in an attempt to reposition classroom with Afrocentricism as a dominant practice in Universities. "Ubuntugogy" as a transformational deviation from the Americentric teaching and learning is adopted as a theoretical framework. The study is situated in the transformative paradigm because its focus is to propose "ubuntugogy" as a way to deconstruct Eurocentric hegemony in university classrooms. Critical Emancipatory Research CER as an epistemological movement that is channelled towards emancipation and freedom from ideological enslavement is used as research design, and the participants consist of 10 people, 5 actively experienced lecturers, and 5 students were selected in the QwaQwa campus of the University of the Free State. Free attitude interview was used to collect data from the participant and the data collected were analysed using Thomas and Harden's three steps of thematic analysis. The study found out that the curriculum and the perpendicular of language and cultural diversities, and colonization of mind and irresistible western classroom system are the significant challenges of implementing "ubuntugogy" in the classroom. The study subsequently proposed curriculum adjustment to accommodate trans-languaging and cultural diversities, and inculcation of self-worth and self-esteem to respond to the western irresistibility in the system with the conclusion that Afrocentric classroom may be one dimensional and thus needs to be redirected to speak to the issues of globalization.
\end{abstract}

Keywords: university classrooms; decoloniality; ubuntugogy; afrocentricism; modernity

\section{Introduction}

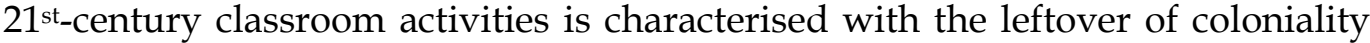
otherwise acknowledged as modernity. Though the spate of modernity sounds progressively inevitable to the echelon of school and schooling, most especially in the global south, its trajectories have become a compulsory devil to the factorisation and production of indigenous knowledge. In our argument, these 
may not wholly take away the beauty of educational advancement and national productivity, but the sociality, socialisation, discoverability and ingenious constructivism are wallowing in the abyss of oblivion. This is supported by Musitha and Mafukata (2018) and Omodan (2019), that the South Africa education system still battling with the consequentiality of the Bantu education. This lacuna is connected to the Eurocentric classroom mapping in our schools. In these observations, no level of education in South Africa is exempted. This may be the reason why Rodney (2012) proposed that "Africa should develop its model of development" to jettison the modernised coloniality and euro-centrism in schools.

In this article, we are joining our proposition with the assumptions of Lebeloane (2018) that the curriculum deserves to be reconstructed to pave ways for the implementers (Teachers/Lectures) who are the major classroom practitioners (Omodan, Ekundayo \& Omodan, 2018). That is, the curriculum must be reconstructed to accommodate ethics and ethos of inclusivity, internalization of indigenous knowledge, disengagement of the indignity of language, indiscriminate sociality, and social justice. By ensuring these postulations, the content knowledge that encompasses self-determined knowledge construction, historically inclined ways of idealizing, pragmatic realities as means of knowing will be determined by the environmental and epistemological realities within learners' conferment. However, the classroom on its own is not abstract, and it does not exist alone without the students, teachers/lecturers and above all, the instinct of actualizing students' achievement and school productivity. This means that human beings are the classroom and to which classroom is set to affect, therefore, to erase the mirage of discourse from the deoloniality, the minds and the mindset of the subjects must be decolonized.

Decolonising the mindset is a confirmation to the fact that Eurocentric and Americentric classroom is not only from the intensity of the coloniality (Mignolo, 2011; Ndlovu-Gatsheni, 2015) but the inability of the colonised to discover the endemic of natural thinking, idealizing and "doing". Hence, the idea of deconstruction of students and teachers/lecturers' mind cannot be disconnected from the classroom decoloniality. Though the curriculum is the guiding principles cum policies for teachers/lecturers and students, but the mindset to bring it to reality is fundamental to individual perspective of the socio-ecological realities of the classroom. From this, the quest to define and redefine own experience beyond the idea of the long-standing coloniality becomes activated. This, as described by Ngũgĩ (1986) as the politics and politicking of language in African literature, is a constructive role in cultural transition, historical reorientation, and love for social identity, which in our argument is called Africanism. From this narrative, one could conclude that the epistemologically "dismembered" ideas as a result of Euro/Americentric pedagogies could be re-launched. 


\section{The place of Curriculum in Afrocentric Pedagogy}

In order to ensure Afrocentricism in the space of Africa education and most especially in classroom ecology, a concerted effort is needed to consistently propel our education documents such as curriculum and other policies that bother more on educational development. A redoubled effort in propelling the idea of Africanising our curricular in South Africa and elsewhere in Africa needs a serious study of the idea of Apartheid and if we have completely de-linked ourselves from its rationality. This is what is needed to be able to delink our epistemological praxis from the westerners. This idea of epistemological disconnection according to Odora-Hoppers and Matiwana (2017) will ensure a perfectly deconstructed Eurocentric way of doing. This according to him is because South African and other African countries still produce knowledge in line with the mirage of modernity. This is to say that the curriculum status quo must be interrogated to establish what appeases the current way of generating knowledge and give credence to ingenious knowledge as a practical concept. This according to Luckett (2016) may not be achieved except if we start questioning the temerity of who decides what counts, what knowledge is valid, and to whom should take the lead, among others. This was supported by Joseph (2017), that in order to dis-expand the colonial archive, the knowledge and the historical development relating to curriculum must be deconstructed.

The school's curriculum itself has been conceptualized from multidisciplinary dimensions to mean what and how, when, and why the education system wants its students to learn an arranged content planned for them in schools. Though arguments exist that curriculum could be planned and thought, most fundamentally could be taught as live (Lebeloane, 2017). This rationale behind curriculum being taught as live, in our view, is to avail the students' enablement to be able to critique the way and process of implementation, which is one of the beauties of decoloniality and "ubuntugogy". In order to ensure unhindered decolonization in university classrooms, the idea of Le Grange (2017) about the various forms of the curriculum cannot be underrated. He deconstructs curriculum in the classroom into two, which are explicit, hidden or null.

The explicit curriculum according to Lebeloane (2017) is a deliberately planned learning content that exposes learners to the exigencies of themselves and their environment, ranging from the past, present and the future. This kind of curriculum according to Le Grange (2017) provides learners with skills to critique, question and ameliorate issues by way of critical thinking. Some of the materials or tools used in the type of curriculum are expert presentations, textbooks, and readers among others. In our argument, it appears that this kind of curriculum could enable learners to individually construct knowledge by the virtue of what he thinks is best because it does allow the student to ask questions to how and why. On the other hand, the hidden curriculum is the one that indoctrinates the practitioners, which include students, teachers, lecturers, among others into the dominant culture and values of the colonisers (Le Grange, 2017; Lebeloane, 2017). This we think is the fact that the content and the freedom to critique and ask questions are not made known or taught in schools. In the quest to decolonize the practical space, one could start to ask questions such as 
5Wh; why, when, what, who, and how. Even the colonization of the mindset may not be far from the hidden curriculum that is ideally Eurocentric.

\section{Situating the Problems as lack of Africanised Pedagogy in the Universities}

In order to challenge the Eurocentric or Americentric classroom "way of doing", the contributions of university education in Africa cannot be underrated. This level of education is the universal community of scholars. This is assumed to contain various pieces of knowledge. It is where the face of a nation, to some extent, is the light to the darkness as created by the coloniality. The problem of this study, therefore, rests on the fact that observations and experiences showed that universities even other levels of education had neglected the aesthetic of indigenous knowledge (Senanayake, 2006; Kaya \& Seleti, 2013). This is to say that, the foreign way of doing has been accepted "hook line and sinker," not minding the locality of the differentiation in the environmental fragmentation, cultural relativism, and the ecological prowess of all the stakeholders both lectures and students are the order of the day. Even the organogram and administrative functionality of the universities is not an exemption. Though this article is only addressing the teaching and learning by defacing the longstanding Eurocentric classroom mapping and replacing it with pedagogy that is fitted to accommodate the use of local knowledge in the process of knowledge construction. This is argued to mean Afrocentric Pedagogy.

However, it is observed that the "natural way of doing", which could mean "indigenous way of doing" is perceived to have been taken away the hegemony of sense of belonging on the part of university teachers and students. This problem could be linked to the national and university curriculum that arrested the Afrocentric classroom constructivism instead of converging with the personal and social needs of curriculum implementers (Odora-Hoppers, 2001). This may have hindered the teachers and students' social dimension of knowledge construction by interpreting the issues below the value and cultural lenses and awareness, making it looks like our own way of doing are below the standard (Van Wyk, 2002). In line with this argument, though knowledge is linked to interest and power domination (Badat, 1997) which is peculiar to current university pedagogy the dominance of the long-standing coloniality in the system. This according to Avis (1996) has regarded knowledge production as hegemonic practices that propagated the rise in poverty, power dominance and social breakdown in general productivity. Besides, our observation also shows that the mindset of teachers, students, and other stakeholder are Eurocentric. Our encounter with many lecturers and students on the trajectories of classroom decoloniality makes me conclude that the mind of the lecturers is somewhat stuck to the implementation of foreign ways of doing, at the expense of cultural and local inclination.

Our encounter with students, most especially those studying science-related courses, showed that many contents in the classroom are completely strange and unable to link them to any concrete and practical realities around them. Among many observations, universities in South Africa, most especially those located in the rural ecology, are far from opening the space for local and or indigenous 
knowledge productions. Even, the instructional materials that are used as aids to learning are not exemplifying or relating to known knowledge. Classrooms in the observed universities have been conducted from the "unknown to unknown" as against "known to unknown" practice. This study is however determined to empirically conceptualise and rationalise decoloniality as a way to bridge the vacuumed of Americentric classroom hegemony.

\section{Theoretical Framework: "Ubuntugogy" as an Approach}

This study is grounded in the concept of "ubuntugogy" which in our view is Afrocentric pedagogy that is rooted in Africanism called "Ubuntu". Ubuntugogy was propounded in 2005 and argued by Bangura to the best-hidden pedagogy, which was branded by the qualities of culturalism, environmentalism, and Afrocentricism (Ganyi \& Owan, 2016). However, "Ubuntugogy" metamorphosed from the philosophy of "Ubuntu"; Ubuntu, etymologically emanated from Xhosa and Zulu languages (Samkange \& Samkange: 1980) which means Humanity and or Humanness (Omodan \& Tsoetsi 2019). This is to say that Ubuntu could be referred to as the quality of being human and humane (Tworeck et al., 2015). These were conceptualised as "a person is a person through others" (Khomba, 2011). From the above, ubuntugogy could be said to mean an Africanised way of teaching and learning. This was conceptualised by Bangura (2017) as an "art and science of teaching and learning that is dominated by humanity and love towards others". From the above, we can make bold to argue along with Ganyi and Owan (2016) that "ubuntugogy" is a transformational deviation from the Amenricentric teaching and learning otherwise called "pedagogy."

Ubuntugogy is, however, a system of teaching and learning that is centered on the utilisation of indigenous and Africanised teaching and learning aids in the classroom where culturalism and environmentalism take the lead (Bangura, 2015) in the teaching and learning input, process and output. This could also be referred to as Afrocentric pedagogy. This theory is relevant in this study because it propels the utilisation and galvanization of culturally and environmentally inclined teaching aids, material and practice to dominate the process of knowledge construction in the classroom. This will enable learners and the teachers and in case of the university system, the students and the lecturers to get along. This could manifest quick knowledge and assimilation because African people are confirmed to crush on the process that enables employment of indigenous spices to discourse. Such an atmosphere enables the lecturers to dispense knowledge from the known to unknown. That is, when classroom content is dispensed and simplified to the students using local examples and materials, it will open their reasoning and be able to link the concept from environmentalism thereby enhance their assimilation. In other to be able to achieve this and inject it into the reality of the university classrooms, the following research question and aim guided the study. 


\section{Research Question and Aim of the Study}

The question of "how to concretize Afrocentric classroom practices to decolonize the euro-centric classroom hegemony" piloted the study. In order to do justices to this empirical discourse, the inconsistencies in the university classrooms and the failure of its system to accommodate Afrocentric constructivism will be explored.

\section{Objectives of the Study}

Based on the research question and aims of the study, the following research objectives paved the way to unravel the problem of Afrocentricism in university classrooms;

- The study investigated the challenges associated with the implementation of Afrocentric Classroom pedagogy.

- The study probed into the possible solution to the challenges with more focus on the implementation of "ubuntugogy".

\section{Methodology}

This is situated in the transformative paradigm because its focus is to propose ubuntugogy as a way to deconstruct Eurocentric hegemony in university classrooms. Besides, the ontology and epistemic stance informing the study is concerned with the social and historical nature in correlation to the classroom reality (Chilisa, 2013). Critical Emancipatory Research (CER) is adopted as a research design for this study, and this is adopted to enable researcher to understand and respond to the issue of classroom sociality and interrogate social justices in the curriculum implementation. In the argument of Dube (2016) and Ngwenyama (1992), CER is a break-away ideology from Frankfurt school which is centered towards reformation. In a similar perspective, CER is an epistemological movement that is channeled towards emancipation and freedom from ideological enslavement (Dube \& Hlalele, 2018). That is, this choice of design exposes the participant to the systematic social and ideological enslavement eroded in Eurocentric pedagogy. CER is, therefore, appropriate to stand as a foundation for this research process because it stands as antiinjustices; it promotes emancipation and encourages freedom in the research process for transformation. The research participants comprise of five university students, and five lecturers in the Qwaqwa campus of the university of the Free State, South Africa, totaling ten participants, who are active in classroom activities, the selected student were fourth year and postgraduate honour students who are assumed to be much experienced in university pedagogy. The selected lecturers are those with at least four years' experience in the system with active classroom experience.

Free attitude interview was used to collect data from the participant; this method of data generation is considered appropriate because it enables the participants to discuss the issue as it appears to them. Free attitude interview is regarded as a conversation that uncovers real thoughts about a particular phenomenon (Creswell et al., 2016), and it helps the researcher to understand people, their sociality, and the nature of the problem they live with (Mahoko, Omodan \& Tsotetsi, 2019). The data collected was analysed using three steps of 
analysis prescribed by (Thomas \& Harden, 2008), these steps according to them involve coding text, developing descriptive themes, and generating analytical meaning from the coded text. This becomes relevant to this study because it enables the researcher to arrange the data according to the objectives of the study. This further ensures the readers a coherence and cohesion of understanding of the research and its findings.

\section{Results and Findings}

The results from this study were informed by the implementation of the methodological stance as stated above, the principle of CER as research design was fully followed and the data generated through the interview were coded, schematised and analysed based on the objectives of the study. The objectives were to explore the challenges associated with the implementation of the Afrocentric teaching-learning system in the University classroom and to provide possible solutions to the challenges to establish the need for Africanism in the classroom.

\section{The challenges associated with the implementation of Afrocentric Classroom pedagogy}

Sub-themes under objective one that was analysed based on themes from the raw data are; curriculum and the perpendicular of language and cultural diversities, and colonization of mind and irresistible western classroom system. These were derived from the participants' statements and triangulated with literature. For stressless reading, the Lecturers were represented as LT while students were represented as ST in the analysis below;

\subsection{Curriculum and the Perpendicular of Language and Cultural diversities}

Delinking, separating, and or distancing learners from Eurocentric pedagogy in university classrooms could not be done in isolation if at all it is going to see the light of the day. This is because no system of teaching and learning exist without curriculum or policy backup, not only which, the language of teaching and learning is also essential in classroom activities, management, and knowledge production. This in line with the fact that curriculum and other policy document is needed to delink epistemological praxis that could ensure a complete disconnection of eurocentric knowledge construct (Odora-Hoppers \& Matiwana, 2017) from educational practitioners and replace it with Africentric way of doing and thinking. This is the ideal that is expected in the reality of this discourse but the reverse is the case in the system as the participants' statements seem to contradict. See the statements below;

LT2: "Inadequacy of indigenous instructors in schools has made all of us accept foreign classroom culture as the best and it remains like that"

LT3: "Lack of resources relevant to the curriculum/shortage of textual resources to refer to... Lessons that could incorporate Indigenous Knowledge could be time-consuming" 
The statement from LT1 lament that even there are approval ways with which the classroom could be decolonised in the way of using "ubuntugogy", there are limited lecturers who can understand and implement the niti-gritty of such idea. These scenarios according to him have practically made the people more westernized to the extent that it may be difficult to retrace the hegemony of Eurocentric in African classroom mostly in universities. Lack of human capital such as lecturer to implement indigenous knowledge across the classes is the only contributing factor to the challenges, but lack and shortage of locally inclined materials and school resources according to the statement of LT3 is not helping the mater. His idea could mean that the use of indigenous teaching aids may exist but are not enough to ensure consistent use of indigenized teaching aids all the time. The last statement of the LT3 also confirmed that the use of indigenized teaching aids is not time friendly. To think of it, the intention is to say that the use will not allow the lecturer to quickly address the needed issues in classroom as and when due. This is not practically far from the fact that the curriculum and/or the policy book that is piloting the university education in South Africa is either silent or inactive about the incorporation of local content.

The use or not of this indigenized teaching and learning at times is not the sole problem of the lecturer. According to the participants' statements, it bothers more on the issue of diversities in South African classrooms. See the following statements;

LT5: "Since a classroom consists of diversity, another challenge would be, to know which IK from which cultures would be more relevant in a diverse classroom..."

ST1: "Afrocentric education/ curriculum is one dimensional and does may not speak to the issues of the global context and therefore in an everevolving world where the education system seeks to produce 21st century and global citizens, Afrocentric curricula may be irrelevant as it only speaks to the history of one people".

In the statement of LT5, one could confirm that the trajectory of classroom diversities in South Africa, that is, that classroom consists of people from different cultures that come with different socio-political-economic and cultural backgrounds. In this case, it may be difficult for a lecturer to choose which indigenous artefact or history and ways of going is better employed. Besides, the lecturer may even not be familiar with more than one of two cultural and environmental backgrounds. Therefore, such a teacher does not have a choice than to use generally accepted teaching practices in the classroom. This is not far from the analysis of ST1, who stressed that the Afrocentric curriculum is one dimensional too and does not accommodate diversities of people that can support the best global practice. This according to her is irrelevant. Moreover, our understanding is because Afrocentric pedagogy may not accommodate the people's choice, most notably in the university system, where people from various countries converge in the search for knowledge. However, the issue of diversity that comes with language differences surface and because more problematic to the implementation of indigenous knowledge. This is confirmed by the responses below; 
LT2 "Considering the place of African languages in the in a Eurocentric society. Can they coexist or does it have to be either one of the languages"

ST3: "It is difficult to even begin believing in African ways of life in this political era, most especially in the classroom. So, in other words, African pedagogy still needs a lot of development for curriculum purposes"

The statement from LT2 gives a severe concern about the possibility of having one language as Africans, which is practically in our view not achievement anytime soon. Even in a country, there are many languages, South Africa, for example, has up to 12 different languages that come with their peculiarities, etc. This is in line with the argument of Ngũgi (1986) which states that there are politics and politicking of language in African literature that clamoured for social identity. This idea is not in isolation as the ST3 confirmed that it is challenging to believe in the African way of life as a result of the unstable political system that has characterized the continent. Maybe this statement is coming as a result of politics that has been involving in the formulation and implementation of policies and even curriculum. This trust diversion may not be the focus of this study, but it gives meaning to the reason why many implementers may not even trust the people in power for curriculum and policy formulations. He further stressed that African pedagogy needs a very long way to go. From the above, it is evidenced that curriculum and university education policies are not very kin in the inculcation of Africanized way of practices in the classroom and that the Language in the place of diversities is a significant challenge in the classroom that is diverse like South Africa.

This finding is supported by Joseph (2017), that the only way to ensure indignity as against the colonial archive, the knowledge and the historical development relating to curriculum must be deconstructed. From the above analysis, it is therefore found out that the Africanised factors are not yet in the curriculum, and the perpendicular of Language and Cultural diversities is confirmed to be a challenge to the implementation of Africanised knowledge production in the classroom. This finding also goes in consonance with the agitation of Lebeloane (2018) that the curriculum deserves to be reconstructed to pave ways for the implementers. This is practically what the agitation for decoloniality through ubuntugogy is preaching. That is, to ensure the possibilities of Ubuntugogy as a way of decoloniality, the curriculum and languaging will not be an extraneous variable in the process. Because decoloniality and ubuntugogy according to Ganyi and Owan (2016, p. 35) is transformational teaching and learning which could make teaching and learning process more acceptably productive to students.

\subsection{Colonisation of Mind and Irresistible Western Classroom System}

This challenge is not new in the education system, and it is perceived that the system is inclined with the western way of doing that is uneasy to be dismantled based on its long-standing practices of modernity. This idea is not too far from what has dominated the mind of the lecturers and the students. This according to Van Wyk (2002) have hindered the socially constructed knowledge and interpretation of values and culturalism because the westernized mindset of the practitioners portraits the Africanised way of doing as below standards. This is 
evident in the fact that knowledge is linked to interest and power domination (Badat, 1997), which is the dominance of the long-standing coloniality in the universities. This has gone a long way to congest the mindset of the people to believing that only acceptable ways of doing are the westernized and anything short of that is targeted uncivilized. This does not only exist in our observations and literature but also in the participants' statements as illustrated below;

LT1: "Inferiority complex is the case, lectures and parents alike believe that using indigenous languages in the classroom setting will rubbish their personalities, hence their continuous insistence on the use of foreign languages"

ST4: "Western knowledge has reduced African knowledge into fiction and ridiculed it to something that is unorthodox"

ST4: "beside the classroom, even there is no much-written work that is in the African context"

From these statements, one could confirm that there is decolonization of life, thinking and doing. The statement of LT1, confirmed that there is an inferiority complex among the lecturers and the parents. This is evidence according to him that parent is not confident in the locally way of doing things thereby will find it difficult to enroll their children in such schools. Furthermore, there is a feeling that using indigenous language or classroom practice is proof that such may be tagged as rubbish and thereby affecting their social personalities. Because of this, they prefer to engrain themselves in the assumed civilized (westernized) ways. This complex as examined above according to ST4 confirms that western knowledge as reduced African knowledge to nothing and making it look like a fiction that is wallowing in the illusion of reality. This is not palatable but in reality, that is what is playing to the gallery. That is why the perceptions of people are that the British schools that operate within the British curriculum are better than the national curriculum ones. This challenge according to ST4 is not only peculiar to this perceived systematic marginalization but also in the world of records. The ST4 stresses that there is not much written that is done in the African context. This may not be that there is no writing that is done is such context but could be that many such have imbibed the westernized content to prove their worth.

From the above analysis, it seems that it may not be easy to completely decolonised classroom for the purpose of re-establishing "ubuntugogy". The reason for this may not be restricted only to the fact that practitioners have been systematically colonised from the aspect of knowledge construction. But another fact emerging from the field is that almost all the practitioners are westerntrained. See the statements below;

LT2: "it is going to be a challenge to decolonise the African classrooms because most of the teachers, as well as the children, are raised in a modern way"

L4: "Influx of foreign teachers/lecturers who do not have indigenous knowledge of teaching into the schools". 
The argument here is that the challenge regarding the implementation of Africanised classroom pedagogy is facing so many extraneous problems such as the fact that many teachers are trained in a westernized manner and as well as students, most of them grown up where there were little or no experience about local and indigenous knowledge. This may not go well even in the ideal and the discourse is coming to reality. This bothers more on the law of realism that says what cannot be seen may not be real. The finding is, therefore, that the mindset and the way of doing of the people in the system are already indebted to colonization and wiliness to promote the persistence coloniality exists among them. On the other hand, western pedagogy and its practices, according to this study, were found to be irresistible, though these findings may not be absolutely defined the mind and the interest of this research location. I, therefore, argue in line with Avis (1996) that production of knowledge in the classroom has been swept under the carpet of Eurocentric practices that have propagated in power dominance and social breakdown in general productivities. This is confirming the true state of Ubuntugogy in universities as opined by Owan (2016) that the best of "ubuntugogy" is still hidden because it was branded with the beauties of culturalism, environmentalism, and Afrocentricism.

\section{Solutions to the challenges of Afrocentric Classroom Pedagogy}

Sub-themes under objective two that were analysed based on themes from the raw data are; curriculum adjustment to accommodate trans-languaging and cultural diversities, and inculcation of self-worth and self-esteem to respond to the irresistibility.

\subsection{Curriculum and or Policy Readjustment to Accommodate Languages and Cultural Diversities}

Based on the above challenges as emanated from the participants alongside the analytical interpretations, one could confirm that the curriculum needs to be readjusted to accommodate the issue of cultural diversities, language differences in order to be able to respond well to the issue and agitations classroom Africanisation. This may not be achievable in isolation, that is, the practical involvement of leaders, most notably, those in the affairs of higher education should ensure that all these agitations are incorporated; this in our argument may equip the practitioners with necessary weapons to deal with the deficiencies and any hidden trajectories of "Ubuntugogy". This call is not only based on our argument, but on the participants' statements also justified the need. See below;

LT3: "Need to identify an Authority saddled with the power to implement the proposed education policy or create one if there exists none for effective implementation of the policy".

From this, one could say all eyes are on the leaders, the curriculum planners, the policymakers to gear up and propound all-inclusive law that will inculcate the spirit of multilingualism that could enhance the learning and the use of multiple languages by the teachers and even the learners. This is pertinent because it is deduced that diversity in terms of language and culture may not allow the 
actualization of Africanised classrooms in the university system. The below statements are also justifying the need though in slightly different manners;

L3: "we need to adopt a far-reaching indigenous language that is sufficient, flexible and trans-ethnically acceptable to operationalize the policy".

ST3: "we need a position to appreciate African languages then we will move into incorporating the African knowledge into the curriculum."

In line with the above, the formulation of inclusive curriculum/policies on education will only survive if it is adapted with "a far-reaching indigenous language that is sufficient, flexible and trans-ethnically acceptable to operationalize the policy". This position will enhance the appreciation of African cultures, language and ways of doing. From this analysis, it is hereby found out that curriculum and or policy readjustment to accommodate languages and cultural diversities is essential, this is not an idea that is in isolation, this is in support of the call by Lebeloane (2017) that there is a need for a deliberately planned curriculum content that will expose students to themselves and the environment by exposing the historical linkage of issues to the present and the future. This is also supporting the conclusion of Grange (2017) that various forms of the curriculum cannot be underrated when it comes to educational transformation.

\subsection{Inculcation of Self Worth and Self Esteem to respond to irresistibility}

Self-worth and self-esteem are one of the factors that strengthen students, teachers, lecturers, and other practitioners, according to Jan et al., (2015) enhance their skills, develop them both mentally and physically. The wellness and ability of the stakeholder as mentioned above are essential in what and how the school operates and implementation of academic plans are done (Omodan, Ekundayo \& Bamikole, 2018). Self-confidence and self-esteem have been found by researchers to be essential in the performance of lecturers and the students (Kususanto, Ismail \& Jamil, 2010; Mbuva, 2016). Going by these, the recommendation of the practitioners' self-efficacy that could promote self-belief and worth among them is not out of place. This is also mentioned in the participants' statement as a means to make bold to defend one history and dimensions of culture, see below;

ST1: Practitioners who are knowledgeable in that area of expertise must come forth and Africanism as a narrative and the true history behind it because there are too many accounts of our history.

LT1: Teachers/lecturers and parents alike should see indigenous languages as keys to all-round improvement and should learn from countries like China, Japan, Germany.

These statements are coming as a perceived result of lack of self-worth, esteem, and efficacy coupled with boldness to display and define oneself to the people. This does not only bother on the lecturers and or students, but Africanism must also be defined and popularised with a carefully defined history that makes unity in diversity. The boldness to defend oneself among many olds also 
accounts for why LT1 admonished that parents and lecturers should see indigeneity as a way of life, as a means for growth and development. The reasons why LT1 referred to countries such as China, Japan, and Germany are because those countries are examples of countries where indignity and traditional ways of doing dominates. Moreover, this has helped them rise among the countries of the world. It is, therefore, found out that inculcation of self-worth and selfesteem to respond to the irresistibility of western ways of doing could be one of the solutions that could enhance the implementation of Africanised ways of doing. This is supported by the finding of Jan, et al. (2015) that building more on the teachers' and students' self-esteem is a panacea of productivities and performance. This could also be linked to the fact that when there is boldness and self-belief, to challenge the hegemony of any kind in the classroom will be activated and any forms of oppression, whether systematic, physical or hidden, will be challenged. This is because self-esteem is essential in the performing abilities of lecturers and the students (Mbuva, 2016).

\section{Conclusion}

In conclusion, as findings would have it that the challenges of the Afrocentric classroom operation in universities are inabilities of the curriculum to incorporate the principles of Ubuntugogy, and the perpendicular of language and cultural diversities. Another challenge is the colonisation of mind and irresistible western hegemony in the classroom. All these were found to be essential if the agitation will be sustained. Along these, the solutions were provided which includes, the quest that curriculum should be readjusted to accommodate trans-languaging and cultural diversities. Not only that, all the practitioners are also enjoyed to be endowed with entire self-worth and selfesteem needed to respond to the irresistibility of modernity in classrooms. However, the need for mass orientation that focuses on socio-psychological decolonisation of students and lecturers against the Eurocentric influences of modernity towards broad and legitimate acceptance of the proposed Afrocentric pedagogy policy in teaching through the production of indigenous knowledge in the University system. Therefore, Afrocentric education/curriculum may be one dimensional and thus needs to be redirected to speak to the issues of globalization; this will enhance the concept to operate within the ever-evolving world where the education system seeks to produce 21st century and global citizens.

\section{References}

Avis, J. (1996). Knowledge and nationhood: education, politics and work. London: Casse 11.

Badat, S. (1997). Educational politics in the transition period. In: P Kallaway, G Kruss, G Donn \& A Fataar (eds). Education after apartheid: South African education intransition. Cape Town: UCT Press.

Bangura, A. K. (2015) Yoruba Gurus and the Idea of Ubuntugogy. In: Toyin Falola and African Epistemologies. Palgrave Macmillan, New York.

Chilisa, B. (2013). Indigenous Research Methodologies. Thousand Oaks: Sage. https://doi.org/10.4102/aej.v1i1.44.

Creswell, J. W., Ebersohn, L., Eloff, I., Ferreira, R., Ivankova, N. V., Jansen, J. D., \& Dube, B. (2016). A socio-religious hybridity strategy to respond to the problems of 
religious studies in Zimbabwe (Ph.D Thesis). Faculty of Education, University of The Free State, South Africa.

Dube, B., \& Hlalele, D. (2018). Engaging in critical emancipatory research as an alternative to mitigate school violence in South Africa. Education Research for Social Change, 7(2), 74-86. https://doi.org/10.17159/2221-4070/2018/v7i2a5

Ganyi, F. M., \& Owan, J. I. (2016). Impact of Transculturalism and Globalization on the Concepts of Oral Literature and "Ubuntugogy" as Educational Paradigms for African Liberation and Development in the 21st Century. English Language, Literature E Culture, 1(3), 30-39. https://doi.org/10.11648/j.ellc.20160103.13

Jan, F., Khan, I., Khan, S., Khan, M. R., \& Saif, N. (2015). The Factors Affecting Teachers' Self-esteem in the Higher Educational Institutions. Research on Humanities and Social Sciences, 5(9), 132-135.

Kaya, H. O., \& Seleti, Y. N. (2013). African indigenous knowledge systems and relevance of higher education in South Africa. The International Education Journal: Comparative Perspectives, 2013, 12(1), 30-44.

Khomba, K. J. (2011). Redesigning the balance scorecard model: An African Perspective. (Ph.D Thesis). University of Pretoria, South Africa.

Kususanto, P., Ismail, H. N., \& Jamil, H. (2010). Students' Self-Esteem and their Perception of Teacher Behavior: A Study of Between-Class Ability Grouping. Electronic Journal of Research in Educational Psychology, 8(2), 707-724. https:// doi.org/10.25115/ejrep.v8i21.1395

Lebeloane, L., (2018). Decolonizing the school curriculum for equity and social justice in South Africa. KOERS - Bulletin for Christian Scholarship, 82(3). Retrieved from https://doi.org/10.19108/KOERS.82.3.2333

Mahoko N., Omodan B. I., \& Tsotetsi C. T. (2019). Managing Teachers' Passion in Rural Secondary School: An Asset-based Approach. (16-23). International Conference on Social Science and Economics. Johannesburg, South Africa on 25th-26th July 2019.

Mbuva, J. (2016). Exploring Teachers' Self-Esteem and Its Effects on Teaching, Students' Learning and Self-Esteem. Journal of Higher Education Theory and Practice, 16(5), 59-68.

Mignolo, W. (2011). The Darker Side of Western Modernity: Global Futures, Decolonial Options. Durham: Duke UP. https:// doi.org/10.1215/9780822394501

Musitha, M. E., \& Mafukata, M. A., (2018), 'Crisis of decolonising education: Curriculum implementation in Limpopo Province of South Africa'. Africa's Public Service Delivery and Performance Review, 6(1), a179. https:// doi.org/10.4102/apsdpr. V6i1.179

Ndlovu-Gatsheni, S. J., (2015), 'Decoloniality as the future of Africa'. History Compass, 13(10), 485-496. https://doi.org/10.1111/hic3.12264

Ngugi, W. (1986). Decolonising the Mind: The Politics of Language in African Literature. London: James Currey. https:/ / doi.org/10.2307/40143257

Ngwenyama, O. K. (1990). The critical social theory approach to information systems: Problems and challenges. Michigan: University of Michigan. https://doi.org/10.4135/9781849209687.n7

Odora-Hoppers, C. (2001). Decolonizing the curriculum, indigenous knowledge systems and globalization. Pretoria: HSRC unpublished paper.

Omodan, B. I. (2019). Democratic Pedagogy in South Africa: A Rethinking Viewpoint for knowledge Construction. Journal of Social Studies Education Research, 10(2), 188203.

Omodan, B. I., Ekundayo, H. T., \& Bamikole, O. I. (2018). Enhancing students' academic performance in secondary schools: The Vicissitude of Classroom Management Skills. The International Journal of Business \& Management, 6(11), 106-112. 
Omodan, T. C., \& Tsotetsi, C. T. (2019). Framing Ubuntu Philosophy to Reconstruct Principals' Behaviour and Teachers' effectiveness in Secondary Schools. Journal of Education Research and Rural Community Development, 1(1), 25-45.

Rodney, W., (2012), How Europe underdeveloped Africa. Pambazuka, Dakar. https://doi.org/10.2307/20048265

Samkange, S. J. T., \& Amkange, T. M. (1980). Humanism or Ubuntuism: A Zimbabwe Indigenous Political Philosophy. Salisbury: Graham Publishers.

Senanayake, S. G. J. N. (2006). Indigenous knowledge as a key to sustainable development. The Journal of Agricultural Sciences, 2(1), 87-94. https:// doi.org/10.4038/jas.v2i1.8117

Thomas, J., \& Harden, A. (2008). Methods for the thematic synthesis of qualitative research in systematic reviews. BMC Med. Res. Methodology, 8, 45-65. https://doi.org/10.1186/1471-2288-8-45

Tworeck, C., Hemminga, D., Huber, D., \& Dhillon, D. (2015). The Ubuntu philosophy as a management Strategy. https:// doi.org/10.13140/RG.2.2.10116.01925

Van Wyk, J. (2002). Indigenous Knowledge Systems: implications for natural science and technology teaching and learning. South African Journal of Education, 22(4) 305312. 